Available online at $\quad$ http://www.jfas.info

\title{
CALCULATION OF THE CLOSE PACKING OF FINE AGGREGATE ON THE BASIS OF SCREENING FOR FINE GRAINED CONCRETE
}

\author{
V. V. Strokova*, Y. V. Fomenko, K. G. Sobolev, N. O. Kuzmina \\ Federal State-Funded Educational Institution of Higher Education «Belgorod State \\ Technological University named after V.G. Shoukhov» Russia, 308012, Belgorod, Kostukova \\ street, 46
}

Published online: 08 August 2017

\begin{abstract}
The paper considers the calculation of the maximum packing density of fine aggregate. The selection of the granulometric composition of the aggregate is given. The bulk densities and packing densities of standard screening fractions were determined. The content of each fraction in the mixture and the packing density of the aggregate mixture are calculated by the introduction of a subsequent finer fraction. Topological calculation of sandstone screening was performed. The results of sieving of sandstone screening are presented. The high-density grain composition of aggregate for fine-grained concrete is obtained. The compositions of concrete mixtures have been designed. The volume ratio of aggregate and cement paste in the concrete mix, the average mass size of the aggregate grains in the mixture, the volume fractions of cement and water in the concrete mixture are determined. The physicomechanical characteristics of fine-grained concrete of various compositions with a high density aggregate are shown. Results of testing the control samples for compressive strength are given. The density of the obtained samples was determined. Conclusions are drawn on the work.
\end{abstract}

Keywords: Fine-grained concrete, fine aggregate, granulometry, screenings, sandstone, highdensity aggregate

Author Correspondence, e-mail: author@gmail.com

doi: http://dx.doi.org/10.4314/jfas.v9i2s.82 


\section{INTRODUCTION}

Selection of the granulometric composition of the aggregate is performed in order to achieve the maximum packing density of grains and their minimum voidness, which allows to significantly reduce the binder consumption. In addition, obtaining a high-density aggregate composition under the condition of complete coating and minimal spreading of aggregate grains with a cement test makes it possible to increase the strength of the material by engaging the aggregate in the work and creating a structural framework that takes part of the destructive load [1-5].

\section{Main part}

The calculation was carried out for the screening of quartzite sandstone crushing, which is a waste of the mining and processing enterprise public corporation «Lebedinsky mining processing plant (Lebedinsky GOK)» (Russia). The size modulus of screening of sandstone $\mathrm{M}_{\mathrm{k}}=3,7$. The average density is $1520 \mathrm{~kg} / \mathrm{m}^{3}$, the true density is $2710 \mathrm{~kg} / \mathrm{m}^{3}$, the bulk density is $1415 \mathrm{~kg} / \mathrm{m}^{3}$. The particle size distribution is shown in Table 1 .

Table 1. Granulometric composition of sandstone screening

\begin{tabular}{|c|c|c|c|c|c|c|}
\hline \multicolumn{7}{|c|}{ Residue on the sieve, \% diameter, mm } \\
\hline more than 5 & $5-2,5$ & $2,5-1,25$ & $1,25-0,63$ & $0,63-0,315$ & $0,315-0,16$ & less than 0,16 \\
\hline 1 & 28 & 16,5 & 29,5 & 22,5 & 1 & 1,5 \\
\hline
\end{tabular}

To perform a topological calculation, the sandstone screenings of the Lebedinsky deposit with maximal size $10 \mathrm{~mm}$ was screened by standard sieves with a cell size of $10 ; 5 ; 2.5 ; 1.25 ; 0.63$, 0.315 and $0.14 \mathrm{~mm}$ (Table 2).

Table 2. Granulometric composition of sandstone screening of the Lebedinsky mining processing plant

\begin{tabular}{|l|c|c|c|c|}
\hline Size fraction, $\mathrm{mm}$ & Sampleweight, $\mathrm{g}$ & Partial residuals, $\mathrm{g}$ & $\begin{array}{c}\text { Partial residuals, } \\
\%\end{array}$ & Total residuals, \% \\
\hline $10 \ldots 5$ & 1590 & & & \\
\hline $5 \ldots 2,5$ & 1555 & 1555 & 29,4 & 29,4 \\
\hline $2,5 \ldots 1,25$ & 495 & 495 & 9,4 & 38,8 \\
\hline $1,25 \ldots 0,63$ & 750 & 750 & 14,2 & 53,0 \\
\hline $0,63 \ldots 0,315$ & 605 & 605 & 11,5 & 64,5 \\
\hline $0,315 \ldots 0,14$ & 1005 & 1005 & 19,0 & 83,5 \\
\hline$<0,14$ & 870 & 870 & 16,5 & 100 \\
\hline Total & 6870 & 5280 & 100 & \\
\hline
\end{tabular}


For each fraction, the bulk density in the dry state and the bulk density in the aqueous medium in the vibrocompacted state were determined. The packing density of each fraction was calculated by the formula [6]:

$$
\eta=\left(\rho_{b} / \rho_{a v}\right)
$$

where $[\mathrm{rho}]_{\mathrm{b}},[\mathrm{rho}]_{\mathrm{av}}$ - the bulk and average densities of each fraction respectively; for sandstone the average density was assumed equal to $2650 \mathrm{~kg} / \mathrm{m}^{3}$. The results of the studies are given in Table 3 and Figure 1.

Table 3. Bulk density and packing density of standard fractions of sandstone screenings 10-0 $\mathrm{mm}$

\begin{tabular}{|c|c|c|c|c|}
\hline \multirow{2}{*}{$\begin{array}{c}\text { Screensize(siev } \\
\text { e residue) }\end{array}$} & bulk density $\rho_{\mathrm{b}}, \mathrm{g} / \mathrm{cm}^{3}$ & packing density & $\begin{array}{c}\text { in the aqueous medium } \\
\text { bulk density } \rho_{\mathrm{b}}, \\
\mathrm{g} / \mathrm{cm}^{3}\end{array}$ & packing density \\
\hline 5 & 1,485 & 0,560 & 1,545 & 0,583 \\
\hline 2,5 & 1,510 & 0,569 & 1,515 & 0,572 \\
\hline 1,25 & 1,535 & 0,579 & 1,639 & 0,619 \\
\hline 0,63 & 1,495 & 0,564 & 1,612 & 0,608 \\
\hline 0,315 & 1,461 & 0,551 & 1,682 & 0,635 \\
\hline 0,14 & 1,522 & 0,574 & 1,594 & 0,601 \\
\hline 0 & 1,508 & 0,569 & 1,579 & 0,596 \\
\hline
\end{tabular}


$a$

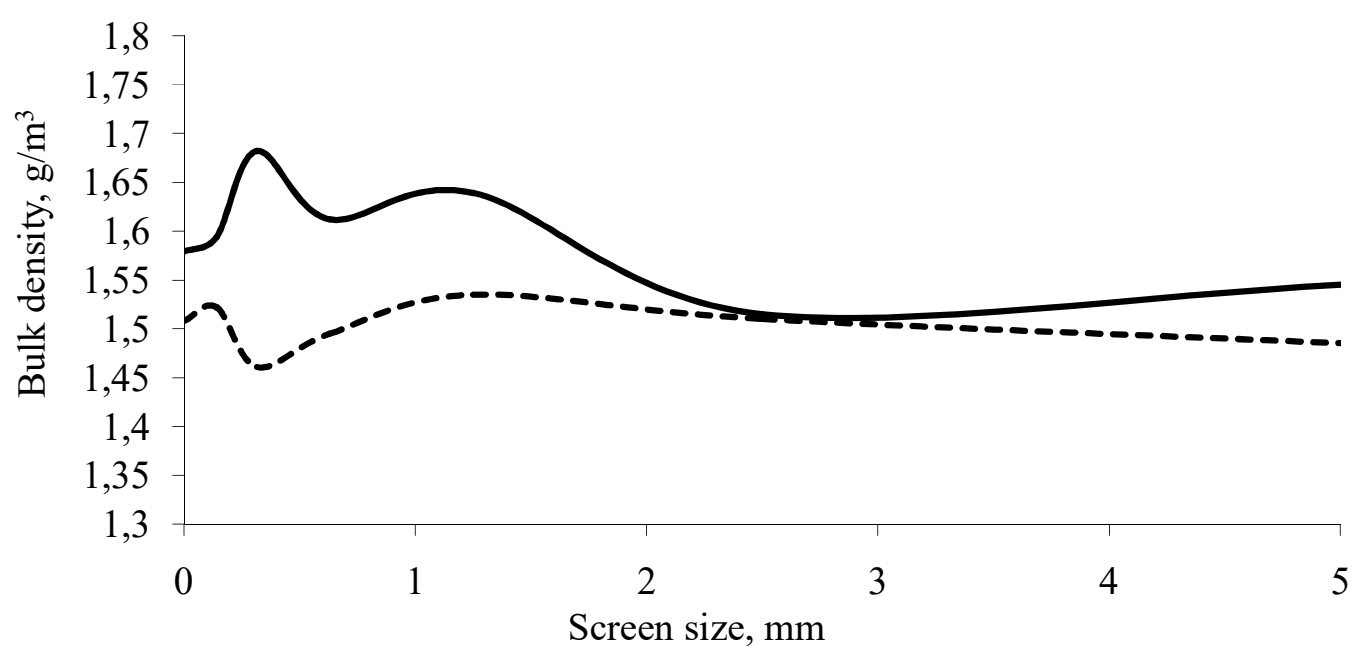

---dry state $\quad$ in the aqueous medium

$\boldsymbol{b}$

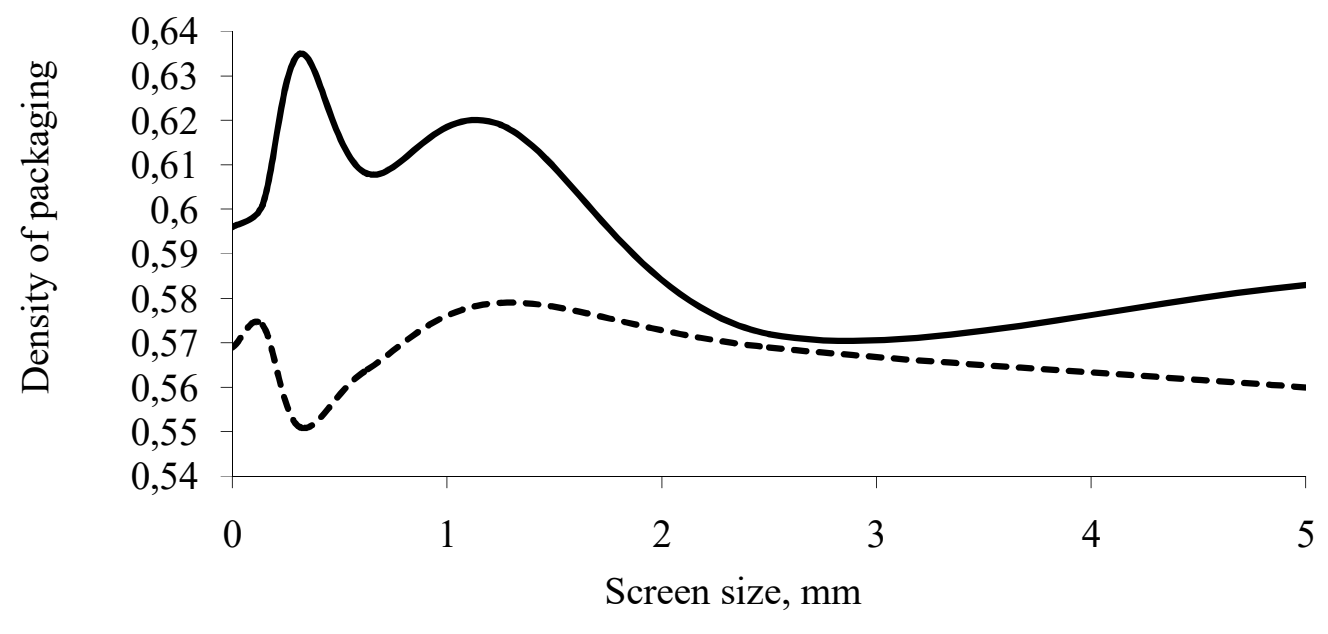

- - $\quad$ in the aqueous medium

Fig.1. Results of sandstone screenings sieving $\mathrm{a}$ - bulk density, $\mathrm{b}$ - packing density

The average grain size of the aggregate dn of each subsequent fraction introduced into the mixture is determined depending on the granulometry class (m), as well as the characteristics of the largest fraction according to the previously established regularity [6]:

$$
\mathrm{d}_{\mathrm{n}}=\left(0,2549 / \eta_{1}\right)^{\mathrm{m}(\mathrm{n}-1) / 3} \mathrm{~d}_{1},
$$

where $d_{1}$ - average grain size of the largest aggregate fraction, with $d_{\max }=10 \mathrm{~mm}$

$$
d_{1}=\sqrt{d_{\max } \times d_{\min }}=\sqrt{10 \mathrm{~mm} \times 5 \mathrm{~mm}}=\sqrt{50}=7,07 \mathrm{~mm} ;
$$


$\mathrm{n}$ - number of the next aggregate fraction introduced into the mixture;

$\eta_{1}$ - the packing density of the grains of the filler of the first fraction with a size of $10 \ldots 5$ $\mathrm{mm}$, in our case $\eta_{1}=0,583$.

For cement concrete it is recommended to use a filler with the granulometry continuity class $\mathrm{m}=6$. By calculating the above formula, we get:

$$
\begin{aligned}
& \mathrm{d}_{2}=(0,2549 / 0,583)^{6(2-1) / 3} \cdot 7,07=1,352 \mathrm{~mm}, \\
& \mathrm{~d}_{3}=(0,2549 / 0,583)^{6(3-1) / 3} \cdot 7,07=0,258 \mathrm{~mm},
\end{aligned}
$$

these average sizes correspond to the fractions $2.5 \ldots 1.25$ and $0.315 \ldots 0.14$; the actual average sizes of aggregate grains in each fraction were determined as

$$
\begin{gathered}
d_{2}=\sqrt{d_{\text {max }} \cdot d_{\text {min }}}=\sqrt{2,5 \cdot 1,25}=\sqrt{3,125}=1,77 \mathrm{~mm}, \\
d_{3}=\sqrt{d_{\text {max }} \cdot d_{\text {min }}}=\sqrt{0,315 \cdot 0,14}=\sqrt{0,0441}=0,21 \mathrm{~mm} .
\end{gathered}
$$

To calculate the content of each fraction in the mixture and the packing density of the aggregate mixture with the introduction of a subsequent finer fraction we take the mass fraction of the largest fraction of $10 \ldots 5$ as one $(\mathrm{G} 1=1)$ [7]. Then the quantity of each subsequent smaller fraction, introduced into the mixture for dense filling of the remaining free volume in the layer, is determined by the formula:

$$
G_{n}=\left(1-\sigma_{n-1}\right) \cdot \beta_{n} \cdot \frac{\eta_{n}}{\sigma_{n-1}} \cdot \sum_{i=1}^{n-1} G_{i}
$$

где $[\text { sigma }]_{\mathrm{n}-1}$ - packing ratio of the mixture consisting of $\mathrm{n}-1$ fractions;

$[\mathrm{eta}]_{\mathrm{n}}$ - the packing factor of the next fine fraction introduced into the mixture;

[beta $]_{\mathrm{n}}$ - coefficient of expansion of aggregate grains with the introduction of each subsequent smaller fraction; for aggregates for coarse aggregate cement concrete it is recommended 11,1 , for fine grained $-1,2$, we take $[\text { beta }]_{\mathrm{n}}=1,2$.

The packing ratio of particles in a high-density mixture of $n$ fractions is calculated by the formula:

$$
\begin{gathered}
\sigma_{n}=\sigma_{n-1}+\frac{\left(1-\sigma_{n-1}\right)}{\beta_{n}} \cdot X_{n}, \\
X_{n}=\frac{\sum_{i=1}^{n-1} \sum_{j=i+1}^{n} \psi_{i j}^{m}}{n / 2 \cdot(n-1)} .
\end{gathered}
$$

The values of $[\mathrm{psi}]_{\mathrm{i}, \mathrm{j}}{ }^{(\mathrm{m})}$ as a function of $\mathrm{m}$ are given in Table 4 . 
Table 4. Dependence of the degree of filling of a free volume in a layer of granular material on the degree of the distribution system

\begin{tabular}{|c|c|}
\hline $\mathrm{M}$ & {$[p s i]_{i j}{ }^{m}$} \\
\hline 0 & {$[\text { epsilon }]_{i}^{3}[\text { eta }]_{i}^{3}$} \\
\hline 1 & {$[\text { epsilon }]_{\mathrm{i}}^{2}[\text { eta }]_{\mathrm{i}}^{3}$} \\
\hline 2 & {$[\text { epsilon }]_{\mathrm{i}}^{2}[\text { eta }]_{\mathrm{i}}^{2}$} \\
\hline 3 & {$[\text { epsilon }]_{\mathrm{i}}^{2}[\text { eta }]_{\mathrm{i}}$} \\
\hline 4 & [epsilon $_{\mathrm{i}}^{2}$ \\
\hline 5 & {$[\text { epsilon }]_{\mathrm{i}}^{2} /[\text { eta }]_{\mathrm{i}}$} \\
\hline 6 & [epsilon $]_{\mathrm{i}}[\text { eta }]_{\mathrm{i}}$ \\
\hline 7 & {$[\text { epsilon }]_{i}^{2} /[\text { eta }]_{i}^{2}$} \\
\hline 8 & [epsilon] $]_{\mathrm{i}}$ \\
\hline 9 & {$[\text { eta }]_{i}^{2}$} \\
\hline 10 & [epsilon] $]_{\mathrm{i}} / \eta_{\mathrm{i}}$ \\
\hline 11 & $1-[\text { eta }]_{i}^{2}$ \\
\hline 12 & {$[\text { eta }]_{i}$} \\
\hline
\end{tabular}

To determine $\mathrm{X} 2$, we compose a scheme for the distribution of particles in relative dimensions, as shown in Figure 2:

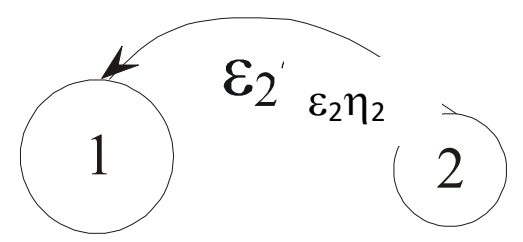

Fig.2. The particle size distribution scheme for determining $X_{2}$

$$
\begin{gathered}
X_{2}=\frac{\left(1-\eta_{2}\right) \eta_{2}}{(2 / 2) \cdot(2-1)}=\frac{(1-0,619) \cdot 0,619}{1}=0,236, \\
\sigma_{2}=\sigma_{1}+\frac{1-\sigma_{1}}{\beta_{2}} X_{2}=0,583+\frac{1-0,583}{1,2} 0,236=0,632, \\
G_{3}=\left(1-\sigma_{2}\right) \cdot \beta_{3} \cdot \frac{\eta_{3}}{\sigma_{2}} \cdot\left(G_{2}+G_{1}\right)=(1-0,632) \cdot 1,2 \cdot \frac{0,601}{0,632} \cdot 1,531=0,634 \text { m.p. }
\end{gathered}
$$

To determine $\mathrm{X}_{3}$, we compose a scheme for the distribution of particles by relative dimensions (Figure 3): 


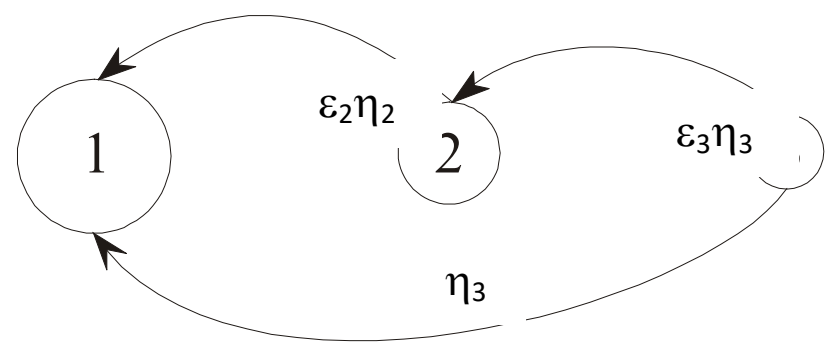

Fig.3. The particle size distribution scheme for determining $X_{3}$

$$
\begin{gathered}
X_{3}=\frac{\left(1-\eta_{2}\right) \eta_{2}+\left(1-\eta_{3}\right) \eta_{3}+\eta_{3}}{(3 / 2) \cdot(3-1)}=\frac{(1-0,619) \cdot 0,619+(1-0,601) \cdot 0,601+0,601}{3}=0,359, \\
\sigma_{3}=\sigma_{2}+\frac{1-\sigma_{2}}{\beta_{3}} X_{3}=0,632+\frac{1-0,632}{1,2} 0,359=0,742
\end{gathered}
$$

We find the percentage content of each fraction in the aggregate mixture:

$$
\begin{gathered}
G_{1}(\%)=G_{1} \cdot 100 \% /\left(G_{1}+G_{2}+G_{3}\right)=1 \cdot 100 \% /(1+0,531+0,643)=46,00 \%, \\
G_{2}(\%)=G_{2} \cdot 100 \% /\left(G_{1}+G_{2}+G_{3}\right)=0,531 \cdot 100 \% /(1+0,531+0,643)=24,43 \%, \\
G_{3}(\%)=G_{3} \cdot 100 \% /\left(G_{1}+G_{2}+G_{3}\right)=0,643 \cdot 100 \% /(1+0,531+0,643)=29,58 \% .
\end{gathered}
$$

We find the expense of each fraction on a $1 \mathrm{~m} 3$ high density aggregate mixture, $\mathrm{kg}$ :

$$
\begin{aligned}
& \mathrm{G}_{1}(\mathrm{~kg})=\mathrm{G}_{1}(\%) \cdot \sigma_{\mathrm{CM}} \cdot 2650 / 100=46,00 \cdot 0,742 \cdot 2650 / 100=904,50, \\
& \mathrm{G}_{2}(\mathrm{~kg})=\mathrm{G}_{2}(\%) \cdot \sigma_{\mathrm{CM}} \cdot 2650 / 100=24,43 \cdot 0,742 \cdot 2650 / 100=480,37, \\
& \mathrm{G}_{3}(\mathrm{~kg})=\mathrm{G}_{3}(\%) \cdot \sigma_{\mathrm{CM}} \cdot 2650 / 100=29,58 \cdot 0,742 \cdot 2650 / 100=581,64 .
\end{aligned}
$$

The obtained high-density composition([eta $]=0,742)$ of fine-grained concrete (Table 5), calculated by the method of A.N. Kharhardin[8-10] has agrain size composition close to the standard screening area (Figure 4) and the absence of grains less than $0.14 \mathrm{~mm}$.

Table 5. High-density grain composition of aggregate for fine-grained concrete

\begin{tabular}{|c|c|c|c|c|c|c|}
\hline $\begin{array}{c}\text { Size } \\
\text { fraction, mm }\end{array}$ & $\begin{array}{c}\text { Consumption, } \\
\text { mass part }\end{array}$ & $\begin{array}{c}\text { Density of } \\
\text { packing in the } \\
\text { mixture with the } \\
\text { introduction of } \\
\text { the n fraction }\end{array}$ & $\begin{array}{c}\text { The content } \\
\text { of fractions } \\
\text { in the } \\
\text { mixture, } \%\end{array}$ & $\begin{array}{c}\text { Consumption, } \\
\mathrm{kg} \text { per } 1 \mathrm{~m}^{3} \text { of } \\
\text { high-density } \\
\text { mixture of } \\
\text { aggregates }\end{array}$ & $\begin{array}{c}\text { Partial } \\
\text { residuals, } \\
\%\end{array}$ & $\begin{array}{c}\text { Total } \\
\text { residuals, } \\
\%\end{array}$ \\
\hline $10 \ldots 5$ & 1,0 & 0,583 & 46,0 & 904,5 & & \\
\hline $2,5 \ldots 1,25$ & 0,531 & 0,632 & 24,4 & 480,4 & 45,2 & 45,2 \\
\hline $0,315 \ldots 0,14$ & 0,632 & 0,742 & 29,6 & 581,6 & 54,8 & 100 \\
\hline Total & 2,174 & & 100 & 1966,5 & & \\
\hline
\end{tabular}




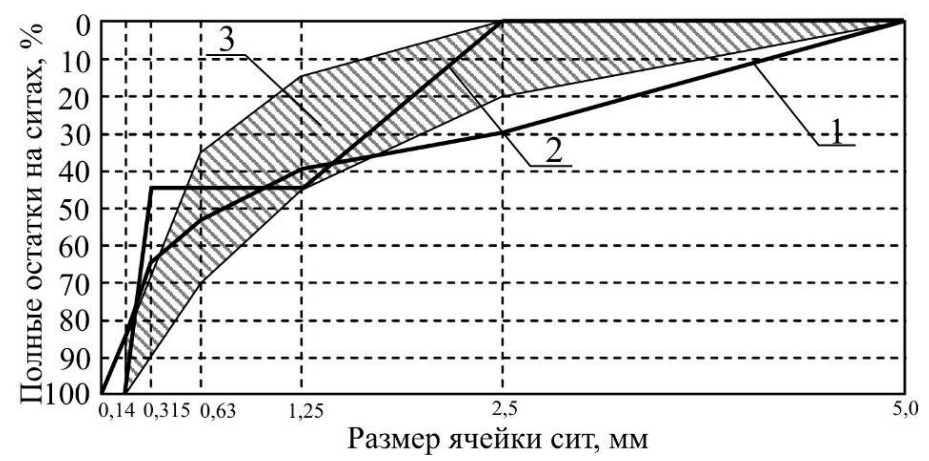

Total residuals, \% / Screensize

Fig.4. Dependence of fractionation of the composition of fine aggregate

when creating high-density packaging:

1 - screening of sandstone; 2 - high-density composition of aggregate; 3 - area of optimal grain composition of fine-grained concrete

Using the obtained high-density mixture of aggregate (Table 5), we design the compositions of concrete mixtures. In the first case, the ratio between binder and aggregate is assumed to be 1: 3; the given ratio is most often used at the enterprises of the construction industry to produce vibro-pressed fine-grained concrete. In the second case, we will determine the ratio based on the thickness of the spreading of the aggregate grains with a cement test equal to 30 $\mu \mathrm{m}$.

The volume ratio of aggregate and cement paste in a concrete mixture is determined by the formulas:

$$
\begin{gathered}
\varphi_{\mathrm{A}}=\frac{\sigma_{\mathrm{CM}}}{\left(1+2 \frac{\delta}{\mathrm{d}_{\mathrm{av}}}\right)^{3}}, \\
\varphi_{\mathrm{CP}}=1-\varphi_{3}
\end{gathered}
$$

where $d_{a v}-$ average mass size of grains in the mixture, $\mathrm{mm}$,

[delta] - the size of the expansion of the grains of the aggregate with a cement test, $\mathrm{mm}$.

Determine the mass-average size of aggregate grains in the mixture:

$$
\begin{gathered}
\mathrm{d}_{\mathrm{av}}=\frac{\mathrm{d}_{1}+\mathrm{G}_{1}+\mathrm{d}_{2}+\mathrm{G}_{2}+\mathrm{d}_{3}+\mathrm{G}_{3}}{\mathrm{G}_{1}+\mathrm{G}_{2}+\mathrm{G}_{3}}=\frac{7,07 \cdot 1+1,77 \cdot 0,465+0,21 \cdot 0,441}{1+0,465+0,441}=4,19 \mathrm{~mm}, \\
\varphi_{\mathrm{A}}=\frac{0,742}{\left(1+2 \frac{0,03}{4,19}\right)^{3}}=0,707, \varphi_{\mathrm{CP}}=1-0,707=0,293 .
\end{gathered}
$$

Determine the volume ratio of cement and water in a concrete mixture:

$$
\varphi_{\mathrm{C}}=\varphi_{\mathrm{CP}} \frac{1}{\left(1+\mathrm{W} / \mathrm{C} \frac{\rho_{\mathrm{C}}}{\rho_{\mathrm{W}}}\right)}=0,293 \frac{1}{\left(1+0,23 \frac{3,1}{1}\right)}=0,171 \text {, }
$$




$$
\varphi_{\mathrm{W}}=\varphi_{\mathrm{CP}} \frac{\mathrm{W} / \mathrm{C}}{\left(\mathrm{W} / \mathrm{C}+\frac{\rho_{\mathrm{W}}}{\rho_{\mathrm{C}}}\right)}=0,293 \frac{0,23}{\left(0,23+\frac{1}{3,1}\right)}=0,122 .
$$

With the knowledge of the volume ratio of aggregate, cement and water in the concrete mix, you can easily determine the consumption of materials in $\mathrm{kg}$ per $1 \mathrm{~m} 3$ of concrete mixture, multiplying the volume fractions by the true density of materials:

$$
\begin{gathered}
\mathrm{C}=\varphi_{\mathrm{C}} \cdot \rho_{\mathrm{C}}=0,171 \cdot 3100=530,1, \\
\mathrm{~W}=\varphi_{\mathrm{W}} \cdot \rho_{\mathrm{W}}=0,122 \cdot 1000=122 \\
\mathrm{~A}=\varphi_{\mathrm{A}} \cdot \rho_{\mathrm{A}}=0,707 \cdot 2650=1873,6, \\
\rho_{\mathrm{CM}}=\mathrm{C}+\mathrm{W}+\mathrm{A}=530,1+122+1873,6=2525,7 \mathrm{~kg} / \mathrm{m}^{3} .
\end{gathered}
$$

Thus, the ratio between binder and aggregate is $\approx 1: .5$.

$$
\begin{aligned}
& A_{1}=A \cdot G_{1}(\%) / 100=1873,6 \cdot 46,00 / 100=861,9, \\
& A_{2}=A \cdot G_{2}(\%) / 100=1873,6 \cdot 24,43 / 100=457,7, \\
& A_{3}=A \cdot G_{3}(\%) / 100=1873,6 \cdot 29,58 / 100=554,2 .
\end{aligned}
$$

\section{CONCLUSION}

Approbation of the influence of the result of the calculation of the maximum packing density on physical and mechanical parameters was carried out on the fine-grained concrete compositions obtained on the basis of cement CEM I $42.5 \mathrm{~N}$ produced by public corporation Belgorodsky Cement, as well as low water demand binder (VNV) with the ratio "cement : quartz component" = 50:50 (VNV-50). When obtaining VNV-50, a superplasticizer Melflux $1641 \mathrm{~F}$ was used. Also for comparison, the factory composition of concrete of the usual composition was used i.e. based on cement and non-fractionated aggregate.

For studies cylinders samples were made with diameter $5 \mathrm{~cm}$ and height $5 \mathrm{~cm}$, volume

$$
\mathrm{V}=\mathrm{S} \cdot \mathrm{h}=\left(3,14 \cdot 2,5^{2} / 5\right) \cdot 5=98,125 \mathrm{~cm}^{3} \text { or } 98,125 \cdot 10^{-6} \mathrm{~m}^{3} .
$$

The control samples were tested for compressive strength (Table 6, Figure 5), and the density of the samples was also determined. 


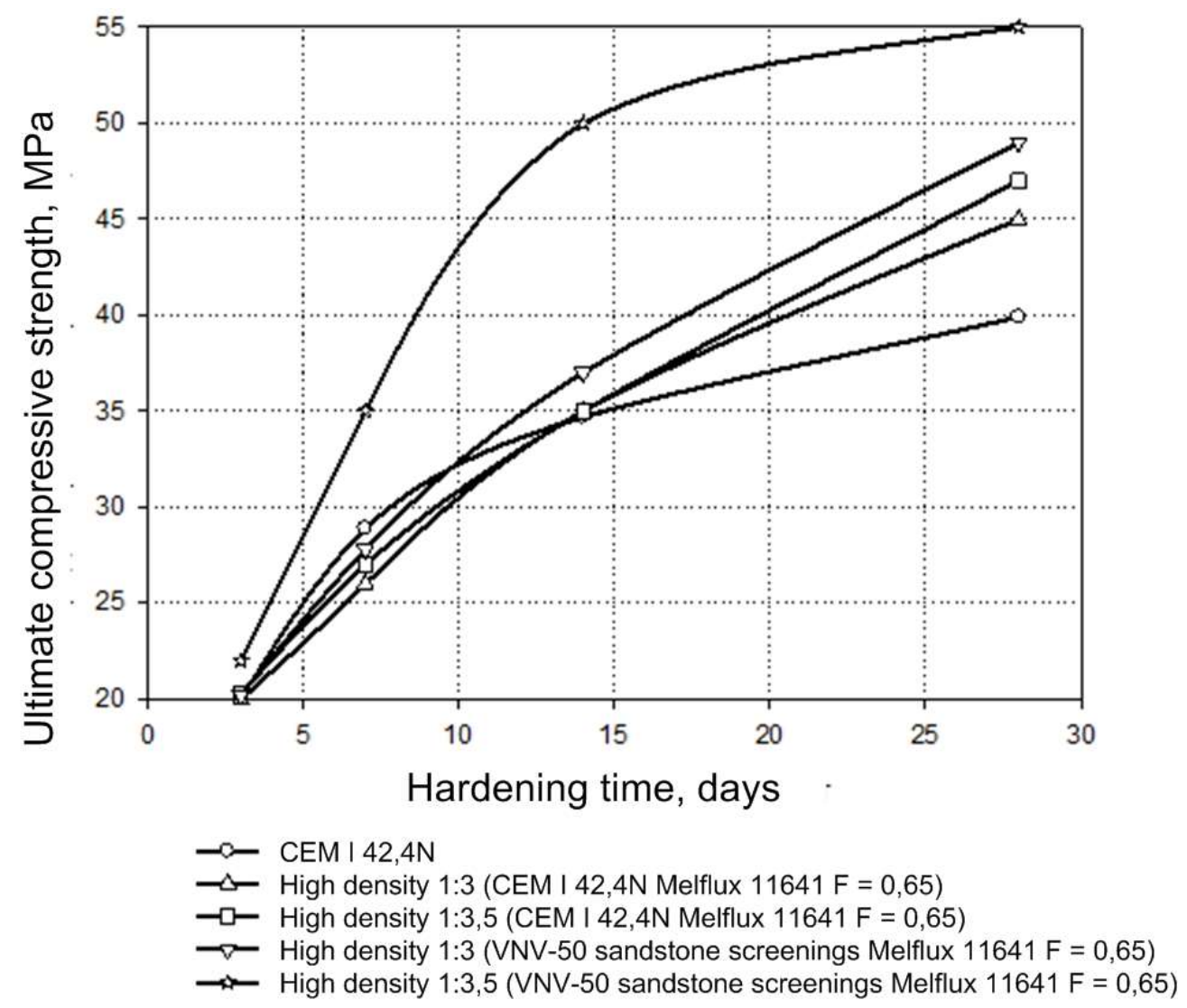

Table 6. Physical and mechanical properties of fine-grained concrete of various compositions with high-density aggregate

\begin{tabular}{|c|c|c|c|c|c|c|c|c|c|c|}
\hline \multirow{2}{*}{$\#$} & \multirow{2}{*}{ Composition } & \multicolumn{3}{|c|}{ Consumption of materials, $\mathrm{kg}$} & \multirow{2}{*}{$\begin{array}{l}\text { Age, } \\
\text { days }\end{array}$} & \multirow{2}{*}{$\begin{array}{l}\mathrm{R}_{\text {comp }}, \\
\mathrm{MPa}\end{array}$} & \multirow{2}{*}{ 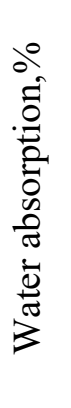 } & \multirow{2}{*}{  } & \multirow{2}{*}{ 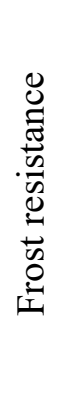 } & \multirow{2}{*}{ 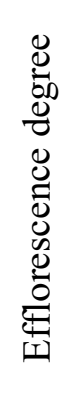 } \\
\hline & & $\begin{array}{l}\text { Binder } \\
\text { (cement) }\end{array}$ & $\begin{array}{l}\text { aggregate } \\
\text { (sandstone } \\
\text { screenings) }\end{array}$ & Water & & & & & & \\
\hline \multirow{4}{*}{1} & \multirow{4}{*}{$\begin{array}{c}\text { Traditional } \\
\text { CEMI 42,5 } \\
\text { H, sand }\end{array}$} & \multirow{4}{*}{561,0} & \multirow{4}{*}{1635} & \multirow{4}{*}{202,0} & 3 & 20,0 & \multirow{4}{*}{5,8} & \multirow{4}{*}{0,59} & \multirow{4}{*}{200} & \multirow{4}{*}{+++} \\
\hline & & & & & 7 & 28,9 & & & & \\
\hline & & & & & 14 & 34,7 & & & & \\
\hline & & & & & 28 & 39,9 & & & & \\
\hline \multirow{2}{*}{2} & High density & 600,0 & \multirow{2}{*}{1800} & \multirow{2}{*}{138,0} & 3 & 20,0 & \multirow{2}{*}{3,3} & \multirow{2}{*}{0,33} & \multirow{2}{*}{200} & \multirow{2}{*}{--- } \\
\hline & $1: 3$ & $(300,0)$ & & & 7 & 26,0 & & & & \\
\hline
\end{tabular}




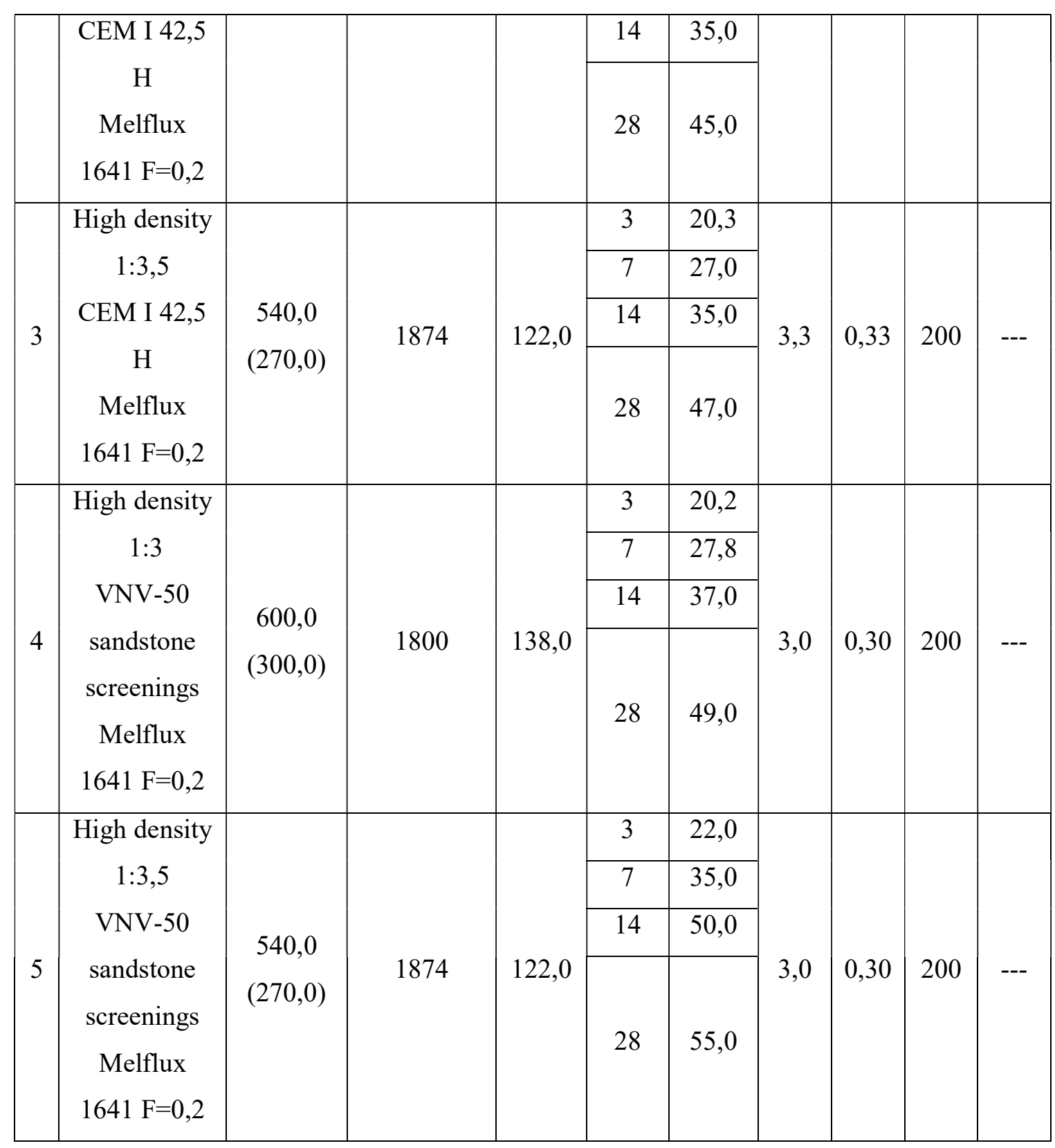

Note: +++ large number efflorescence; + - minor amount of efflorescence; --- no efflorescence

\section{SUMMARY}

Thus, the results of the study showed that the maximum effect is achieved with increasing the ratio of "cement / sandstone screening" with the use of high-density composition from 1/3 to 1/3.5. This makes it possible to reduce the thickness of the spreading of the aggregate grains by a cement test to $30 \mu \mathrm{m}$, and thereby not only increase the strength and density of the material, but also reduce the binder's consumption from 600 to $540 \mathrm{~kg}$. 


\section{ACKNOWLEDGEMENT}

Authors gratefully acknowledge the financial support from Ministry of Education and Science of the Russian Federation, Federal Action Programme «Research and Development in Priority Fields of Science and Technology of Russian Federation for 2014-2020», unique agreement identifier RFMEFI58317X0023.

\section{REFERENCES}

1. Suleymanova L.A., Kara K.A., Suleymanov K.A., Pyrvu A.V., Netsvet D.D., Lukuttsova N.P. The topology of the dispersed phase in gas concrete // Middle East Journal of Scientific Research. 2013. Vol. 18. Issue 10. P. 1492-1498.

2. Volodchenko A.N., Lesovik V.S., Volodchenko A.A., Glagolev E.S., Bogusevich G.G. Energy saving raw materials for the production of new generation silicate materials // International Journal of Pharmacy and Technology. 2016. Vol. 8. Issue 4. P. 22673-22686.

3. Volodchenko A.A., Lesovik V.S., Volodchenko A.N., Glagolev E.S., Zagorodnjuk L.H., Pukharenko Y.V. Composite performance improvement based on non-conventional natural and technogenic raw materials // International Journal of Pharmacy and Technology. 2016. Vol. 8. Issue 3. P. 18856-18867.

4. Alfimova N.I., Sheychenko M.S., Karatsupa S.V., Yakovlev E.A., Kolomatskiy A.S., Shapovalov N.N. Features of application of high-Mg technogenic raw materials as a component of composite binders // Advances in Environmental Biology. 2014. Vol. 8. Issue 13. P. $134-138$.

5. Alfimova N.I., Sheychenko M.S., Karatsupa S.V., Yakovlev E.A., Kolomatskiy A.S., Shapovalov N.N. Features of application of high-Mg technogenic raw materials as a component of composite binders // Advances in Environmental Biology. 2014. Vol. 8. Issue 13. P. $134-138$.

6. Kharkhardin A.N., Suleymanova L.A., Kara K.A., Malyukova M.V., Kozhukhova N.I. The determination of topological properties in polydispersed mixtures on the results of sieve laser and particle size analysis // World Applied Sciences Journal. 2013. Vol. 25. Issue 2. P. 347-353.

7. Kharkhardin A.N., Igor Vladimirivich Z., Marina Ivanovna K., Julia Vladimirovna O. Structural topology of products resulting from dry and wet finding of mineral raw // World Applied Sciences Journal. 2013. Vol. 25 (1). P. 55-60.8.

8. Kharkhardin A.N., Strokova V.V., Kozhukhova N.I., Nelubova V.V. Dimensional 
interval and critical sizes of non-legand nano- and microparticles // IOP Conference Series: Materials Science and Engineering. 2015. Vol. 96. Issue 1-2. Article number 012067.

9. Kharkhardin A.N., Kozhukhova N.I., Strokova V.V. Nano- and micro-sized discreteness levels of substance // International Journal of Advanced Biotechnology and Research. 2016. Vol. 7. Issue 3. P. 920-924.

10. Kharkhardin, A.N., Strokova, V.V., Kozhukhova, N.I. Critical dimension of smallsize particles // 11th World Congress on Computational Mechanics, WCCM 2014, 5th European Conference on Computational Mechanics, ECCM 2014 and 6th European Conference on Computational Fluid Dynamics, ECFD 2014. P. 2221-2228.

\section{How to cite this article:}

Strokova V V, Fomenko Y V, Sobolev K G, Kuzmina N O. Calculation of the close packing of fine aggregate on the basis of screening for fine grained concrete. J. Fundam. Appl. Sci., 2017, 9(2S), 1077-1089. 